\title{
Mathematics of Sustainable and Profitable Management of Fisheries Resources
}

\author{
Constantin Vaillant-Tenzer ${ }^{1,2,3}$ \\ ${ }^{1}$ École Normale Supérieure - PSL: Département d'Etudes cognitives \\ ${ }^{2}$ École Normale Supérieure - PSL: Département des mathématiques et applications \\ ${ }^{3}$ Sorbonne Université - Faculté des Sciences et Ingénieurie \\ ${ }^{1}$ constantin.tenzer@ens.psl.eu
}

October 2020

\begin{abstract}
In this article, it is a question of seeing, from mathematical models, how to optimize the fishery, that is to say, to allow fishermen and women to have maximum gains while preserving the resource. We will see that these objectives are far from being incompatible and even go hand in hand.

I study first with biological models, then with bio-economic models, a fishery where only one species is considered exploited. I then propose models of exploitation of several species in trophic interaction by two different approaches: one with systems of coupled differential equations, the other by game theory with a stochastic epidemic model.

We will be careful to formulate the assumptions and presuppositions of each model. We will also indicate possible improvements suggested by the literature.
\end{abstract}

Keywords : Bioeconomics, Nonlinear models, Stochastic models, Optimisation, N-species prey/predator model.

\section{Contents}

1 Introduction 3

1.1 Historical and scientific framework $\ldots \ldots \ldots \ldots$

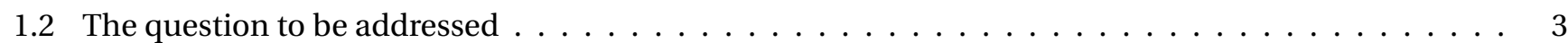

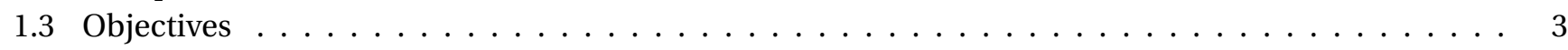

2 Comprehensive biological model of resource development in a mono specific open access fishery 4

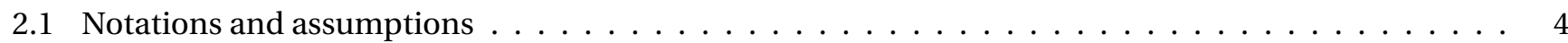

2.2 Differential writing $\ldots \ldots \ldots \ldots \ldots$

2.3 Continuous modeling using differential equations . . . . . . . . . . . . . . . . . . 4

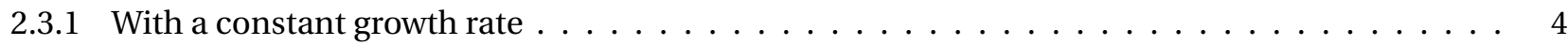

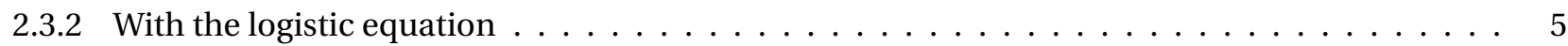

2.4 Sequential models taking into account the different stages of development . . . . . . . . . . . . . 8

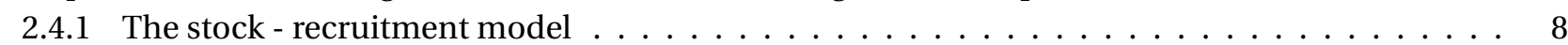

3 Economic analysis: is the ecological optimum the economic optimum? 8

3.1 Explicitation of $h(t, x) \ldots \ldots \ldots \ldots$

3.2 Analysis of the economic optimum $\ldots \ldots \ldots \ldots$

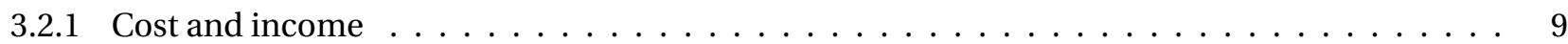

3.2 .2 Maximization of gain in the present moment $\ldots \ldots \ldots \ldots$

3.2 .3 Maximization of the gain to the ecological balance . . . . . . . . . . . . . . . 10

3.3 Optimization over time $\ldots \ldots \ldots \ldots \ldots$

3.3 .1 The integral to maximize . . . . . . . . . . . . . . . . . . . . . . 12

3.3.2 Making money now rather than later: the discount rate comes into play . . . . . . . . . . 12

4 Limitations of a mono-specific model 
5.1 Analysis of several coupled differential equations as a function of the trophic model $\ldots \ldots \ldots$. . . 14

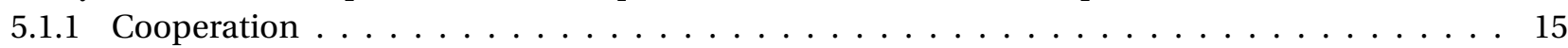

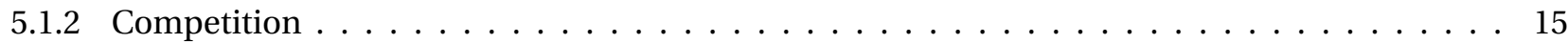

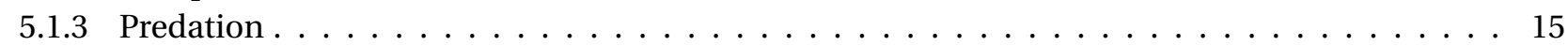

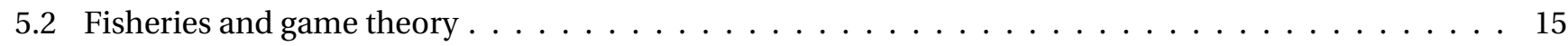

6 Conclusion: what to do? Good fisheries management, the human difficulty of public policy 16

\begin{tabular}{lr}
\hline References & 16
\end{tabular}

\section{List of Figures}

$1 \quad$ Evolution of biomass $x$ (in tons) with exponential growth according to the values of $h$. . . . . . . 5

2 Integral curves of the Verhulst equation for an unexploited species $\ldots \ldots \ldots \ldots$

$3 \quad$ Growth as a function of unexploited population according to Verhulst's model . . . . . . . . . . . . 6

4 Integral curves of the Verhulst equation for a constantly exploited species with $x_{0}=10000$ and $x_{0}=$

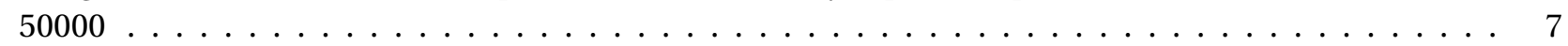

5 Integral curves of the Verhulst equation for a constantly exploited species with $x_{0}=10000$ and $x_{0}=$

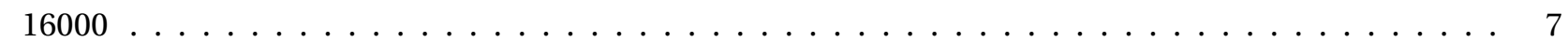

6 Integral curves of the Verhulst equation as a function of $t$ (in years) and $E$ (in year ${ }^{-1}$ ) with $x_{0}=10000$

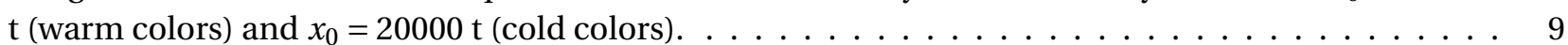

$7 \quad$ Gain $G$ (in euros) depending on $E$ and $t \ldots \ldots \ldots \ldots \ldots \ldots \ldots \ldots$

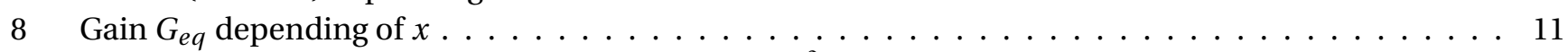

$9 \quad$ Socially Optimal Biomass $x_{\delta}$ according to the ratio $\frac{\delta}{c} \ldots \ldots \ldots \ldots \ldots \ldots \ldots$

\section{List of Tables}

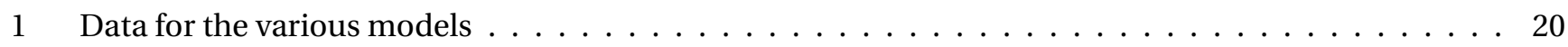

$2 \quad$ Numerical calculation of relevant values for figure analysis $\ldots \ldots \ldots \ldots \ldots \ldots$

\section{Listings}




\section{Introduction}

\subsection{Historical and scientific framework}

Considered until the end of the $19^{\text {th }}$ century as inexhaustible Cur14 , fish resources have been, since the end of the Second World War, victims of over-fishing. As soon as it was observed that stocks were limited, the urgency of better management became apparent. Biologists and economists have therefore taken an interest, in a broader framework, in the modeling of renewable resources and their exploitation.

The first examples of population modeling are, on the one hand, that of Malthus [Mal09] or an exponential growth of the population, still in force today with the use of differential equations [Hol04] [Hol04] and, on the other hand, that of the Fibonacci sequences modeling the growth of a rabbit population. Arino [Ari00] has shown that with linear and non-linear modifications, this suite can be adapted to the modeling of marine populations. But the pioneering mathematical bio-economic modeling on the subject comes from Beaverton and Holst's (1954) [BH54| comprehensive work, whose recruitment model, linking sequentialization, discrete, and differential equations, continuous, serves as a foundation for all other more recent models. During the same period of time, the concept of MSY (maximum sustainable yield), i.e. the maximum number of catches for a population equilibrium, became the main element to be optimized in fisheries [Que93. It is present in all the international treaties on fishing and in the public policies of fisheries management that were implemented since the end of the Second World War throughout the world [Hol04]. However, as we will see below, it is not without serious theoretical problems.

Nevertheless, in spite of the good will of the various stakeholders, fishing catches have stagnated, even decreased, since 1990 while the stocks of more and more species are in a critical state, to the great economic misfortune of the fishermen and women who, unfortunately for them, continue to over-fish, as shown by the latest biannual report of the FAO (2020) on the subject [FAO18]. Colin Clark, in a reference book [Cla90] [Cla10], seeks to explain this paradox by insisting on the importance of the economic equations showing that maximum profitability was obtained with a exploitation of the resource well below MSY. However, he explains that beyond a certain discount rate, the economic optimum in the short term, which then corresponds to finding the fishing effort maximizing an integral over time, may be the extinction of the species. Moreover, the important technological advances in fishing, which allow the tracking of schools of fish with great precision, render, according to Le Floc'h [Le 98], the old models of fishing effort obsolete and, for Cury, deceive the fishermen and women on the real state of the resources [Cur14], depreciating in their eyes the public policies of regulation.

However, solutions to remedy this shortcoming are possible, such as the use of individual transferable quotas proposed by Clark [Cla90] and of which Olivier Guyader gives an example of application [Guy98], or the creation of nature reserves [STC98]. An example showing the relevance of Clark's models is the system of fishermen and women's cooperatives set up in 2007 in Baja California [Van17] which has created micro-reserves which, in addition to increasing income from fishing, generates a tourist activity from which they benefit. These cooperatives sparingly exploit species with high added value, allowing their members to have a high standard of living.

In addition, the failure to take into account interactions between species [Hol04] [Que93] can justify poor management policies. The misuse of MSY reduces the study to a simple prey-predator system while the truth is more complex. The coupling of two species in the catch equations gives completely different results where the growth of one species depends exclusively on that of the other [Cla90]. Igor Kortchemski [Kor14] proposes, via game theory, a very challenging modeling of the prey-predator problem for $N$ species.

\subsection{The question to be addressed}

How to optimize both biologically and economically the management of fishery resources while taking into account the interactions between different species of fish?

\subsection{Objectives}

1. Modelling: I will calculate the optimal bio-economic strategies for the exploitation of a fish reserve by trying several models ;

2. N-body problem: in the previous models, I will characterize mathematically and numerically the contribution of interactions between fish species, first with two species that may have different trophic links between them, then by trying to generalize for $\mathrm{N}$ species; 
3. Numerical simulation: with Python, I will test different numerical values of the parameters of my modeling and analyze the significant differences in results.

\section{Comprehensive biological model of resource development in a mono specific open access fishery}

In this section we will test different models in order to see what are the biological limits to avoid extinction of the species through over-fishing. Each time, we will try to answer the following question: what is the maximum fishing, assumed to be a constant in this section, that we can introduce?

\subsection{Notations and assumptions}

Let be a fishery, a biologically closed marine area. It will be assumed in this part that there is no fish migration outside this area. In addition, it will be assumed that in this area there are fish caught by man, not eating each other. We give these fish the same biological parameters. This is why we place ourselves in a mono-specific approximation. We will be led to criticize these approximations later on.

In the whole part, we will note $t \in \mathbb{R}_{+}^{*}$ the time, expressed in years. When we present modeling parameters, we will note in brackets their explicit functional dependencies a priori. Some dependencies (of the population for example) also depend implicitly on other parameters (of time for example); thus writing $N(x(t)$ ) will not be the same as writing $N(x(t), t)$ : in the latter writing, we will have decided to take into account for example the role of seasons in the birth rate whereas in the first case, there is no explicit dependency with time.

\subsection{Differential writing}

Let,

$$
\begin{aligned}
x: \mathbb{R}_{+}^{*} & \rightarrow \mathbb{R}_{+} \\
t & \longmapsto \text { fish biomass }
\end{aligned}
$$

the number of fishes. We assume it is a class $C^{2}$ function.

We define $N(x, t)$ as the birth rate (number of births per unit of time), which is dependent on population and time, and $D(x, t)$ as the death rate (number of deaths from all causes per unit of time), which is also dependent on population and time. We have, by definition :

$$
\frac{d x}{d t}=N(x, t)-D(x, t)
$$

There are two causes of mortality: natural mortality, noted $M(x, t)$ and fishing mortality, noted $h(x, t)$, which is the number of fish caught per unit of time at a given time. Thus we have :

$$
\frac{d x}{d t}=N(x, t)-M(x, t)-h(x, t)
$$

We will first be interested in determining the natural terms and then the catch terms.

This type of modeling, very frequently used for the study of the population, was systematized for fishing by Schaefer in 1954. [Sch91].

\subsection{Continuous modeling using differential equations}

\subsubsection{With a constant growth rate}

The most intuitive writing of a population growth is Malthusian [Mal09] :

$$
\frac{d x}{d t}=c x(t)-h
$$

With $c$ the growth rate, the number of births minus the number of deaths in a year. This equation is simply solved. By noting $x_{0}$ the number of fish at time $t=0$, we obtain : 


$$
x(t)=\left(x_{0}-\frac{h}{c}\right) e^{c t}+\frac{h}{c}
$$

In order not to be extinct, and thus to fish a maximum, the population must not tend towards 0 when $t$ tends towards infinity, so that $h \leq c x_{0}$. We see moreover on the figure 1 that above this threshold, constant fishing has little effect on the population with this model and the effects are only felt after a certain time.

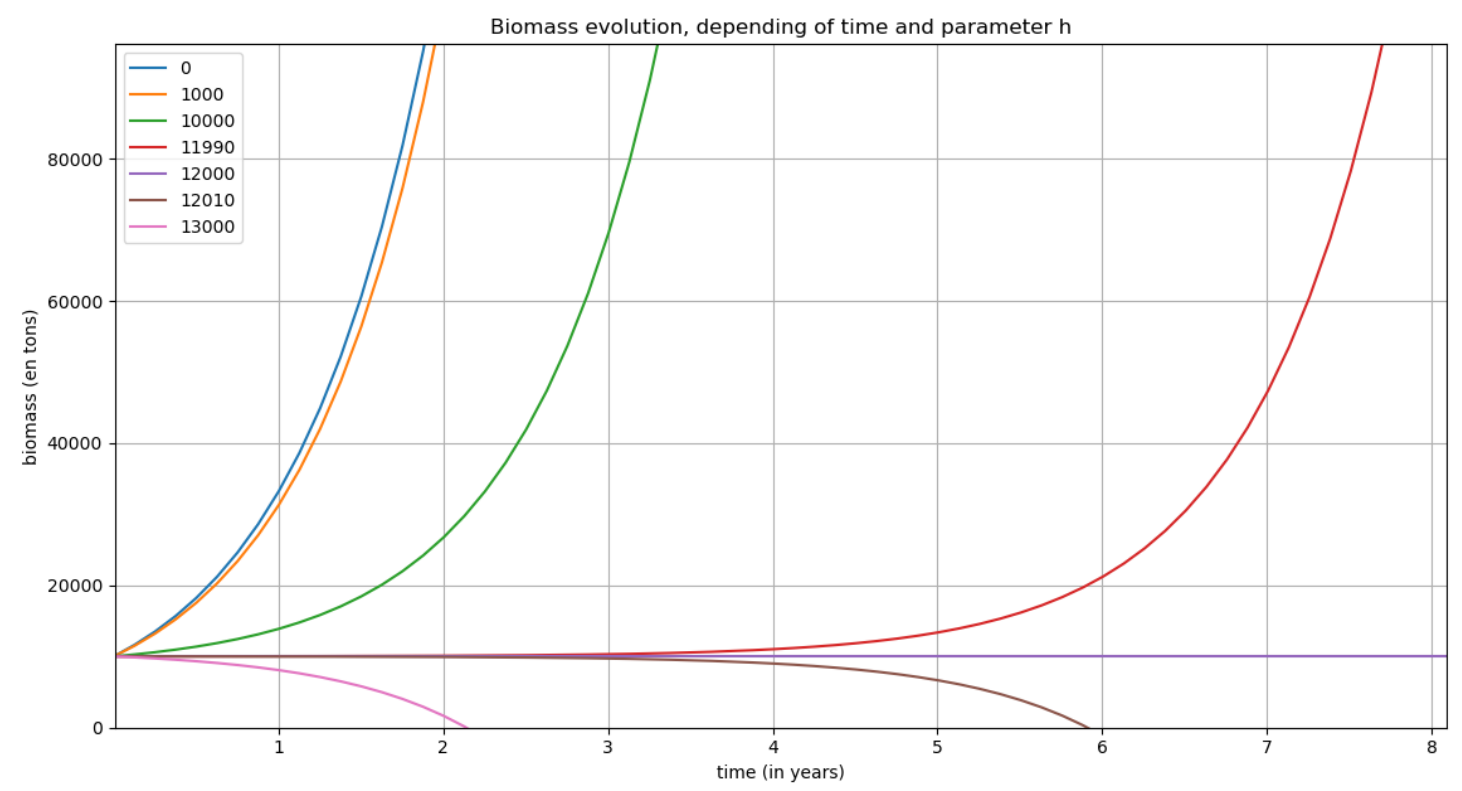

Figure 1: Evolution of biomass $x$ (in tons) with exponential growth according to the values of $h$.

\subsubsection{With the logistic equation}

In general, the natural environment does not allow populations to develop infinitely: fish must share the resources. The environment therefore has a certain maximum capacity $K \in \mathbb{R}_{+}^{*}$. We can therefore write that the environment regulates the population. The $c$ of the previous model thus becomes a function of $x$ and we thus have, by posing again $c \in \mathbb{R}_{+}^{*}$, the intrinsic growth rate of the species (based on the average lifespan and the number of children per individual):

$$
c(x)=c\left(1-\frac{x}{K}\right)
$$

We therefore obtain the following equation, called the logistic equation :

$$
\frac{d x}{d t}=c x(t)\left(1-\frac{x}{K}\right)-h(x, t)
$$

We thus find an equation proposed by Verhlust [Ver38], first applied in bio-economy by Schaefer [Sch91]. Even if this equation can be improved, biologists admit that it is verified in almost all systems, at least asymptotically [Fel40] van+06] [AS10] (see chapter 2).

The associated homogeneous equation is simply solved with a variable separation. Thus, the solution of the equation $\frac{d x}{d t}=c x(t)\left(1-\frac{x}{K}\right)$, here we tool $h=0$, is :

$$
x: t \longmapsto \frac{x_{0}}{\left(1-\frac{x_{0}}{K}\right)\left(e^{-c t}+\frac{x_{0}}{K-x_{0}}\right)}
$$

We notice that the biomass tends to converge after a few years towards a $K$ equilibrium (see figure2]), and thus the derivative cancels itself out infinitely. 


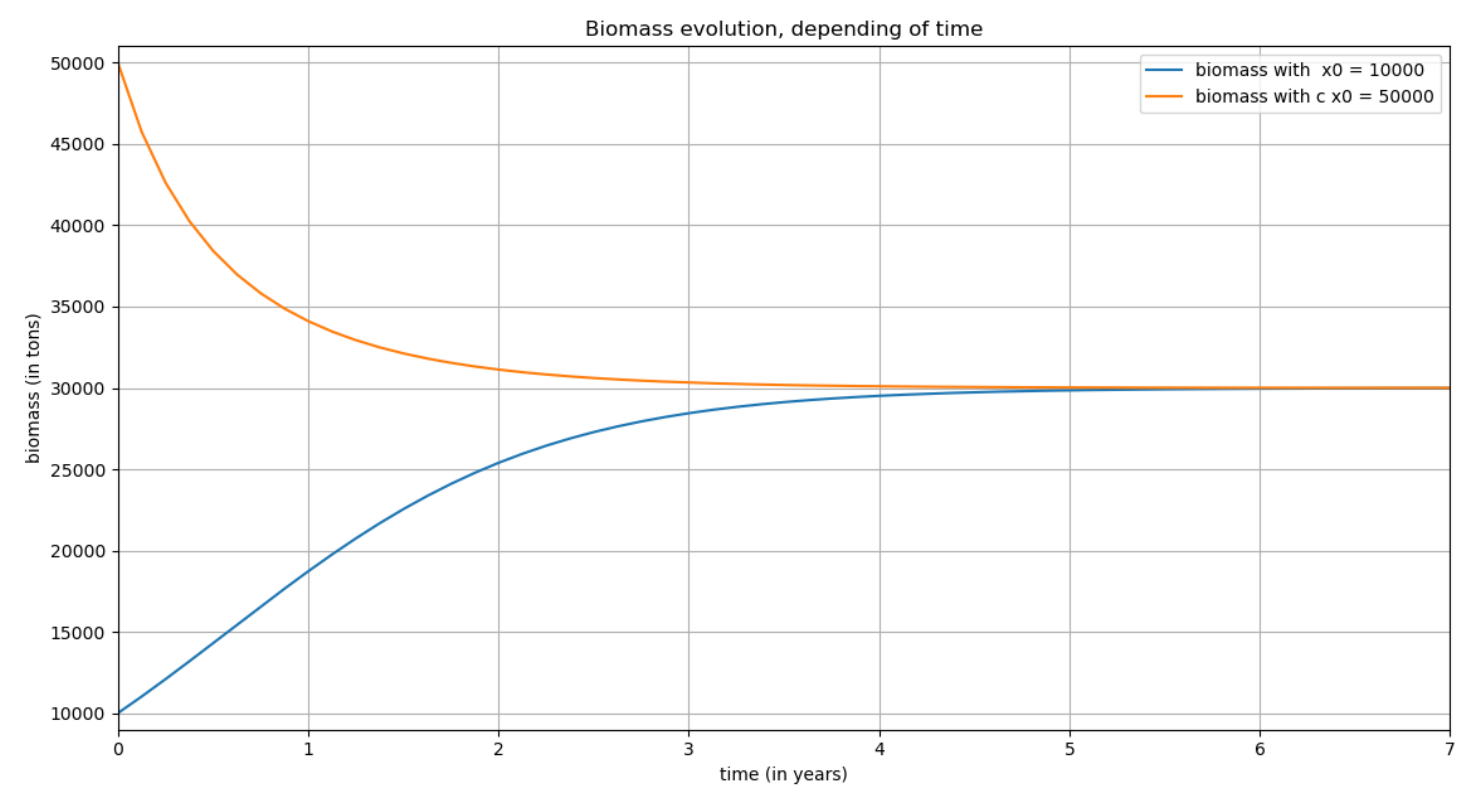

Figure 2: Integral curves of the Verhulst equation for an unexploited species

The integration of the equation, with the particular solution $h$, assumed to be a known positive constant, is problematic since our differential equation is not linear. It gives different results according to $h$ (see figure 3 with numerical integration by the odeint method). However, we can still analyze the extinction conditions.

The maximum population growth is reached for $x=\frac{K}{2}$ (to see this, just cancel the second derivative of $x$ ). We will call this value $x_{M S Y}(15,000$ in the figure 3). MSY stands for Maximum Sustainable Yield, it is the maximum possible growth value for the species, and therefore, the maximum fishing we can do. It has been considered for a long time, often wrongly for both economic (see |Cla06|) and biological (see [Que93| and |[Hol04|) reasons, as the objective to be achieved in fisheries management. This will be explained in the next section.

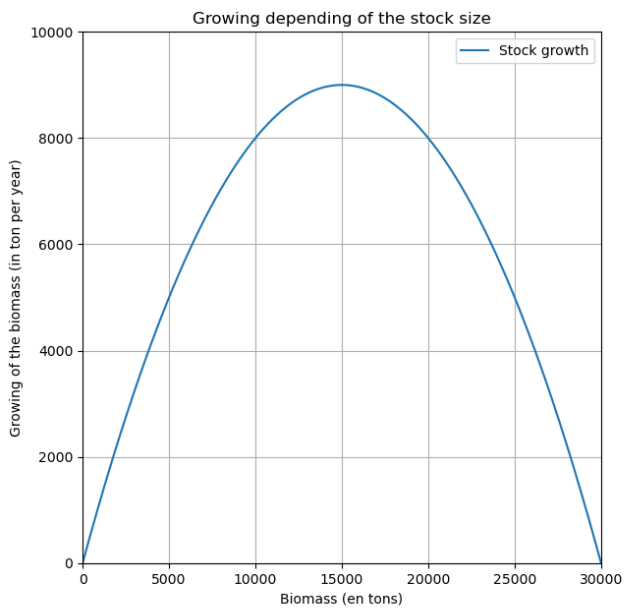

Figure 3: Growth as a function of unexploited population according to Verhulst's model

By injecting this result into the differential equation, we obtain :

$$
M S Y=\frac{d x}{d t}\left(x_{M S Y}\right)=\frac{c K}{4}
$$

Thus, for $\lim _{t \rightarrow \infty} x(t)=x_{M S Y}$, it is necessary that $h=\frac{c K}{4}$. 
However, for this to be sufficient, $x$ must also initially not be both decreasing and less than $x_{M S Y}$. Otherwise, $x$ would reach zero values. In other words, if $x_{0}<x_{M S Y}$, then in order to preserve the resource, $h \leq c x_{0}\left(1-\frac{x_{0}}{K}\right)$ (see figures 4 and 5). We will call this limit value $h_{\max }$. But the optimal long-term strategy would be to let the stock rebuild: i.e., to stop fishing until $x_{0} \geq x_{M S Y}$.

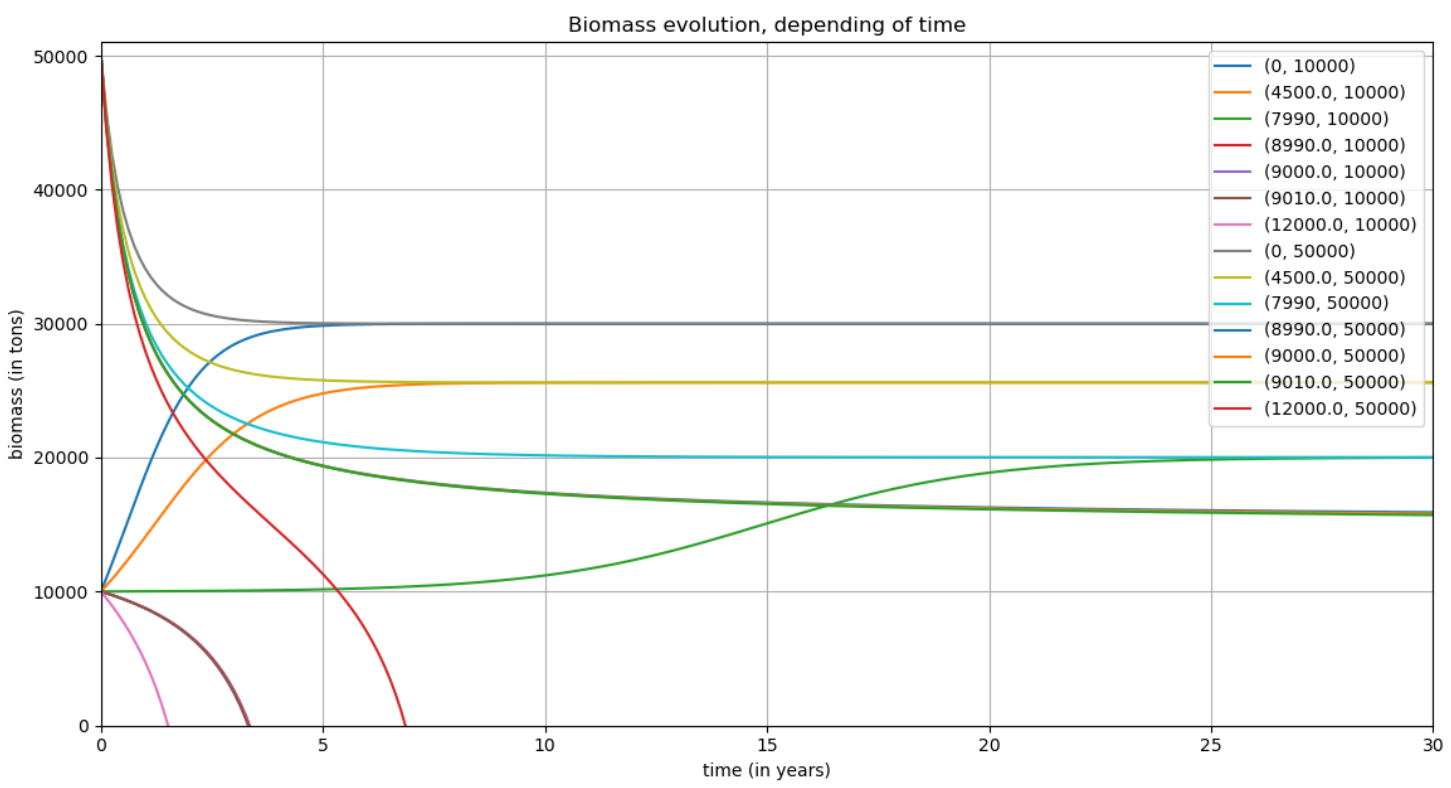

Figure 4: Integral curves of the Verhulst equation for a constantly exploited species with $x_{0}=10000$ and $x_{0}=50000$

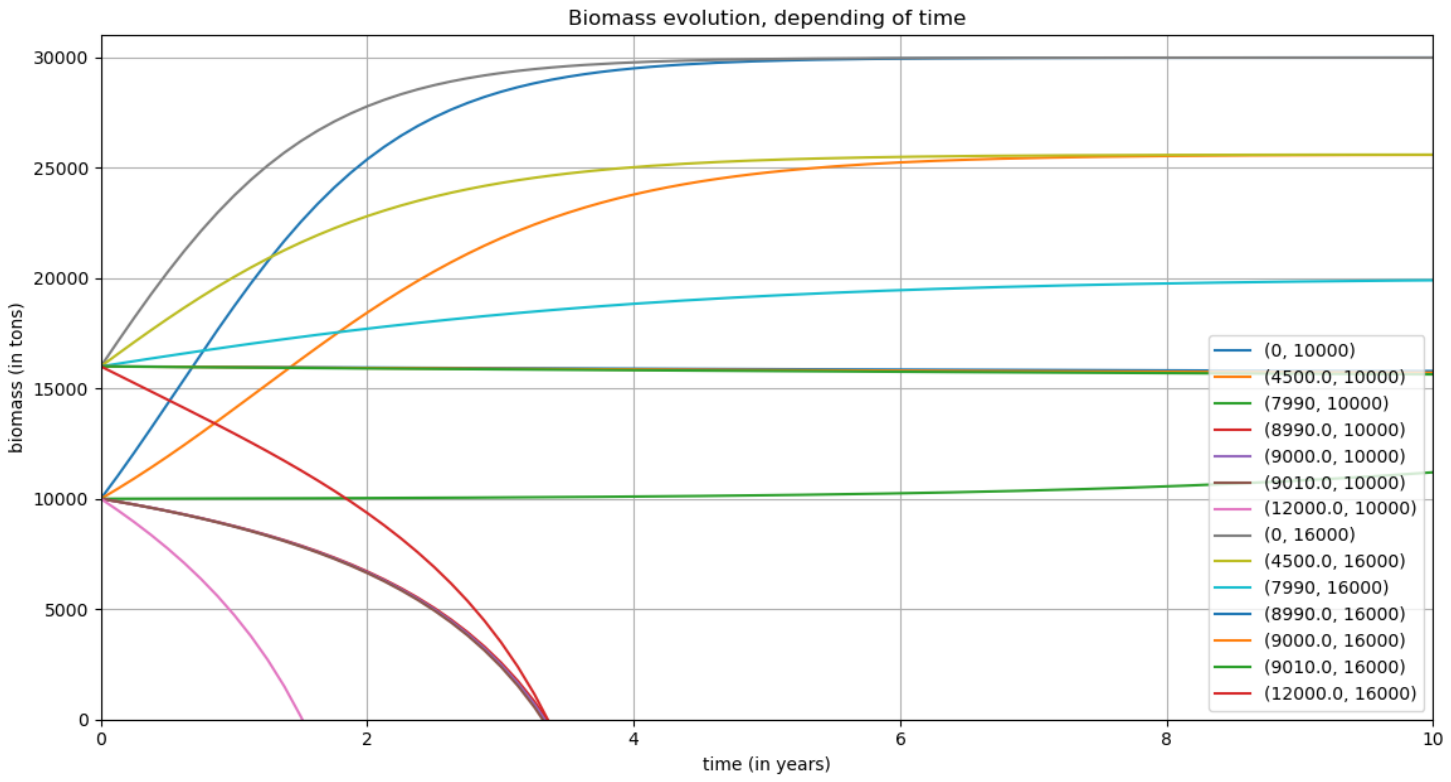

Figure 5: Integral curves of the Verhulst equation for a constantly exploited species with $x_{0}=10000$ and $x_{0}=16000$

This model could be improved by taking into account the seasons [Pau97| (see Chapter 4) as well as the fact that fishing only takes place during daylight hours [DL95]. 


\subsection{Sequential models taking into account the different stages of development}

Historically, the evolution of a population was first represented sequentially, starting with the famous example of the Fibonacci sequences. We can work around this example on [Ari00] fishes. But what is more interesting is to use in our differential calculations the interest of sequentialization: to account for the different stages of development.

\subsubsection{The stock - recruitment model}

Not all ages of a species are usually fished. In addition, each stage of development has a given role in population growth. Often four of them can be distinguished $[\overline{\mathrm{BH} 54} \mid$ : the larval stage, adolescence, the stage where individuals lay eggs and finally the stage where they no longer do.

At each discrete time interval, a proportion $\alpha$ of individuals passes from the $i$ stage to the $i+1$ stage. One can simply make the passage from time $k$ to time $k+1$ continuous by writing the coefficients per unit of time. One must also take into account the laying term, competition and cannibalism between generations, points out [HW01] (see pages 80 to 102). We thus obtain the equations [TG95] for $n$ different stages where mortality $m$ is $a$ priori the sum of natural mortality and fishing:

Therefore, we write, for $i \in\{1, \ldots, n\}$ :

$$
\left\{\begin{array}{l}
\frac{d x_{0}}{d t}=-\left(\alpha-m_{0}-\sum_{i=1}^{n} p_{i} x_{i}(t)-p_{0} x_{0}\right) x_{0}(t)+\sum_{i=1}^{n} f_{i} l_{i} x_{i}(t) \\
\frac{d x_{i}}{d t}=-\left(\alpha-m_{i}\right) x_{i}(t)+\alpha x_{i-1}(t)
\end{array}\right.
$$

This general writing does not, however, account for the role of females, which may be preyed upon differently from males. We therefore have a system of four differential equations. This model is more complete, but the equations are often impossible to solve analytically and often the data can be difficult to find [AS10](p.83). An interesting approach, however, would be to compare it with the results given by the logistic equation, for example by summing each contribution. These models, taking into account the age of the population, are discussed throughout [Pau97].

\section{Economic analysis: is the ecological optimum the economic optimum?}

\subsection{Explicitation of $h(t, x)$}

The ability of a vessel to catch a fish is proportional to the number of fishes in the area. As we consider this over a fairly large area, overall, the distribution is uniform. Then two terms first proposed by Beverton and Holt appear [BH54]. Catchability $q(t) \in[0.1]$ is species-specific and corresponds to the probability of catching the fish for a given catch effort. It increases, very rapidly [Cur14], as a result of the improvement of fishing techniques, equipment [Le 98], and increasingly efficient computer tools [PH06] (conclusion).

However, we will consider in the following $q$ constant. The fishing effort $E(x) \in \mathbb{R}_{+}$corresponds to the direct action of the fishermen and women. Fishing effort is related to the fishing gear used but also to the willingness to fish, which is dependent on the apparent abundance of the stock. We will take in the following constant $E$. The definition of these terms, for which [Lau81] refers to France, and the methods of measurement, often difficult to implement, especially for $q$, have often been discussed [Gas95]. We therefore write :

$$
h(x, t)=q(t) E(x) x=q E x
$$

Thus, the population equation is written:

$$
\frac{d x}{d t}=c x(t)\left(1-\frac{x}{K}\right)-q \operatorname{Ex}(t)
$$

By variable separation, the solution of the differential equation is :

$$
x: t \longmapsto \frac{x_{0}\left(1-\frac{q E}{c}\right) e^{(c-q E) t}}{1-\frac{q E}{c}+\frac{x_{0}}{K}\left(e^{(c-q E) t}-1\right)}
$$

We notice that the equation tends, when $t$ tends towards infinity, towards an equilibrium which we will note $x_{\infty}$ and which is worth : 


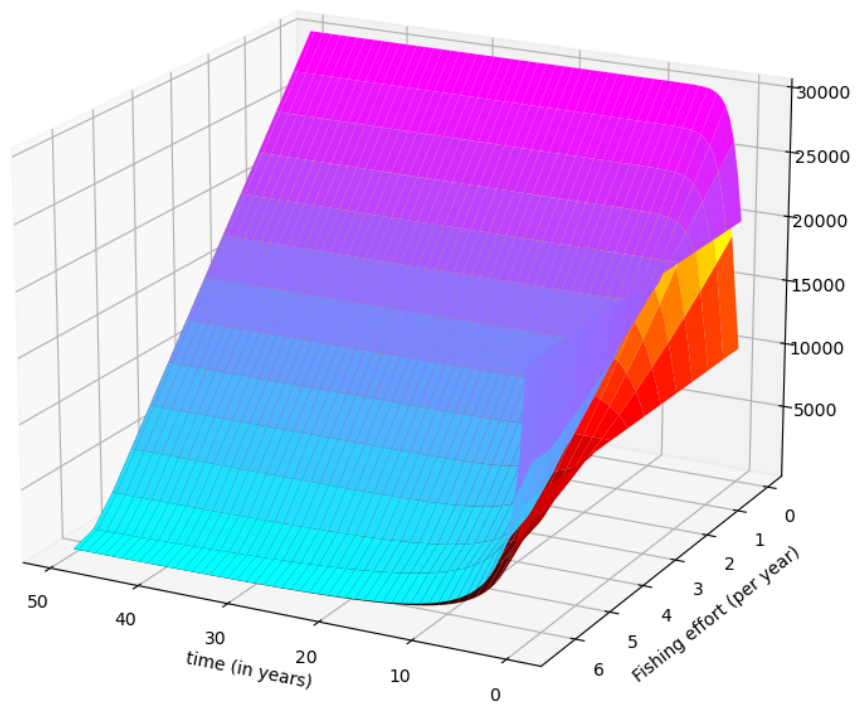

Figure 6: Integral curves of the Verhulst equation as a function of $t$ (in years) and $E$ (in year ${ }^{-1}$ ) with $x_{0}=10000 \mathrm{t}$ (warm colors) and $x_{0}=20000 \mathrm{t}$ (cold colors).

$$
x_{\infty}=K\left(1-\frac{q E}{c}\right)
$$

So we have preservation of the species provided that $E \leq \frac{c}{q}$.

Writing with constant $E$ is far from perfect, and gives results too good to be true [Cla06] (see 2.2). However, improving this model can only be done on a case-by-case basis and requires knowledge of risk management theories. The biological consequences of the fishery will be better described with the models in 5 .

\subsection{Analysis of the economic optimum}

The purpose of this sub-section is to see which solutions are the most cost-effective. The optimum depends on the goal one has set: making money, but now, in the short term or in the long term?

\subsubsection{Cost and income}

The gain per unit of time (in euro.year ${ }^{-1}$ ), at time $t$ corresponds to the revenues minus the costs :

$$
G(x, t)=R(x, t)-C(x, t)
$$

The income comes from the sale of the fish. It corresponds to the fish caught times the price $p \in \mathbb{R}_{+}^{*}$ (in euro.ton ${ }^{-1}$ ). We consider it constant, even if, according to the law of supply and demand, it is a decreasing function of the abundance of the product on the market. However, if our fishery has only a small proportion of the individuals of the species exploited, our modeling is fairly accurate. The income per unit of time is therefore written as :

$$
\begin{aligned}
R(x, t) & =p h(x, t) \\
& =p q E x(t)
\end{aligned}
$$

We will then assume that the cost of exploitation is proportional to the fishing effort by posing $k(t) \in \mathbb{R}_{+}$the cost (in euros) per unit of fishing effort mobilized. The dependence of $k$ over time is mainly due to external political (increase in salary costs) or economic (oil price variations) phenomena. The most reasonable is therefore, 
once again, to assume $k$ constant. This cost does not include the initial investment (the purchase of the fishing boat, for example). Thus :

$$
C(x, t)=k E
$$

Price, like cost, is opportunity, that is, it represents what the fisher earns from fishing a particular species rather than doing something else. This is what gives meaning to our assessment and explains why they are per unit of time. Thus, the gain is worth :

$$
G(x)=p q E x(t)-k E=E(p q x(t)-k)
$$

\subsubsection{Maximization of gain in the present moment}

Here, we will consider $E$ as a positive real variable that we would like to maximize the gain. So $G$ is a function of the positive real variables $E$ and $t$, which we will reduce to a function of $x$.

By inserting the solution of the population equation, we obtain (see figure 7 for the pace) :

$$
G(E, t)=E\left(p q \frac{x_{0}\left(1-\frac{q E}{c}\right) e^{(c-q E) t}}{1-\frac{q E}{c}+\frac{x_{0}}{K}\left(e^{(c-q E) t}-1\right)}-k\right)
$$

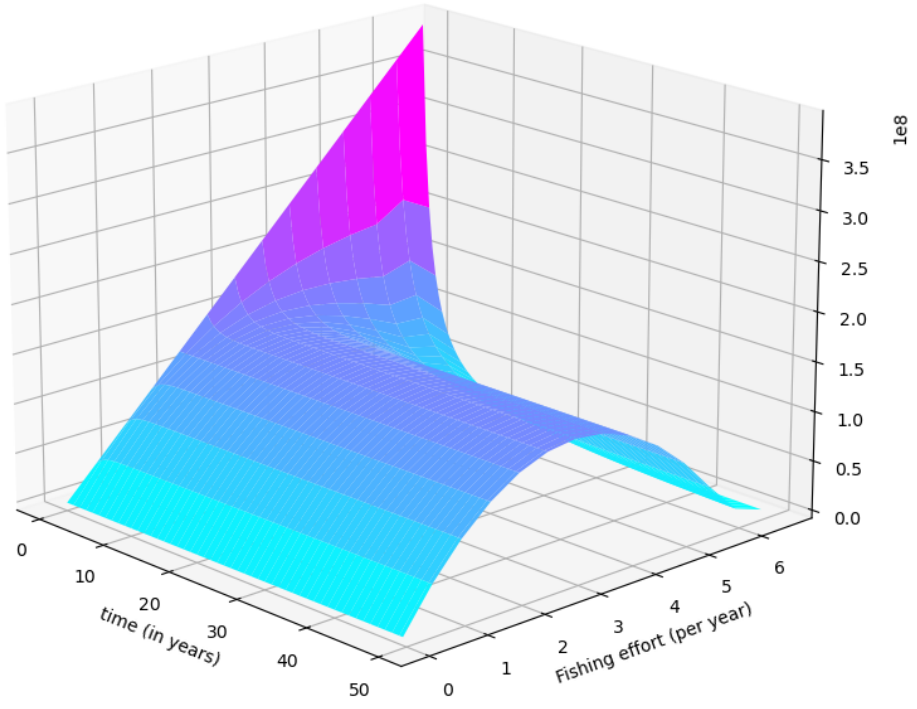

Figure 7: Gain $G$ (in euros) depending on $E$ and $t$

To have a maximum income at a given time $t_{0}$, so for a given $x_{0}$, one must, if $x_{0}>\frac{k}{p q}$ fish as much as possible. Otherwise, the stock should be allowed to build up to have $x$ large enough to fish profitably. We will call this threshold value :

$$
x_{O A}=\frac{k}{p q}
$$

\subsubsection{Maximization of the gain to the ecological balance}

However, if we look at the equilibrium situation, i.e. when $t \rightarrow+\infty$ and therefore : 


$$
\begin{aligned}
\frac{d x}{d t} & =0 \\
c x\left(1-\frac{x}{K}\right)-q E x & =0 \\
h=q E x & =c x\left(1-\frac{x}{K}\right)
\end{aligned}
$$

The gain is written:

$$
\begin{aligned}
G_{e q}(x) & =p q E x-k E \\
& =c\left(p x-\frac{k}{q}\right)\left(1-\frac{x}{K}\right)
\end{aligned}
$$

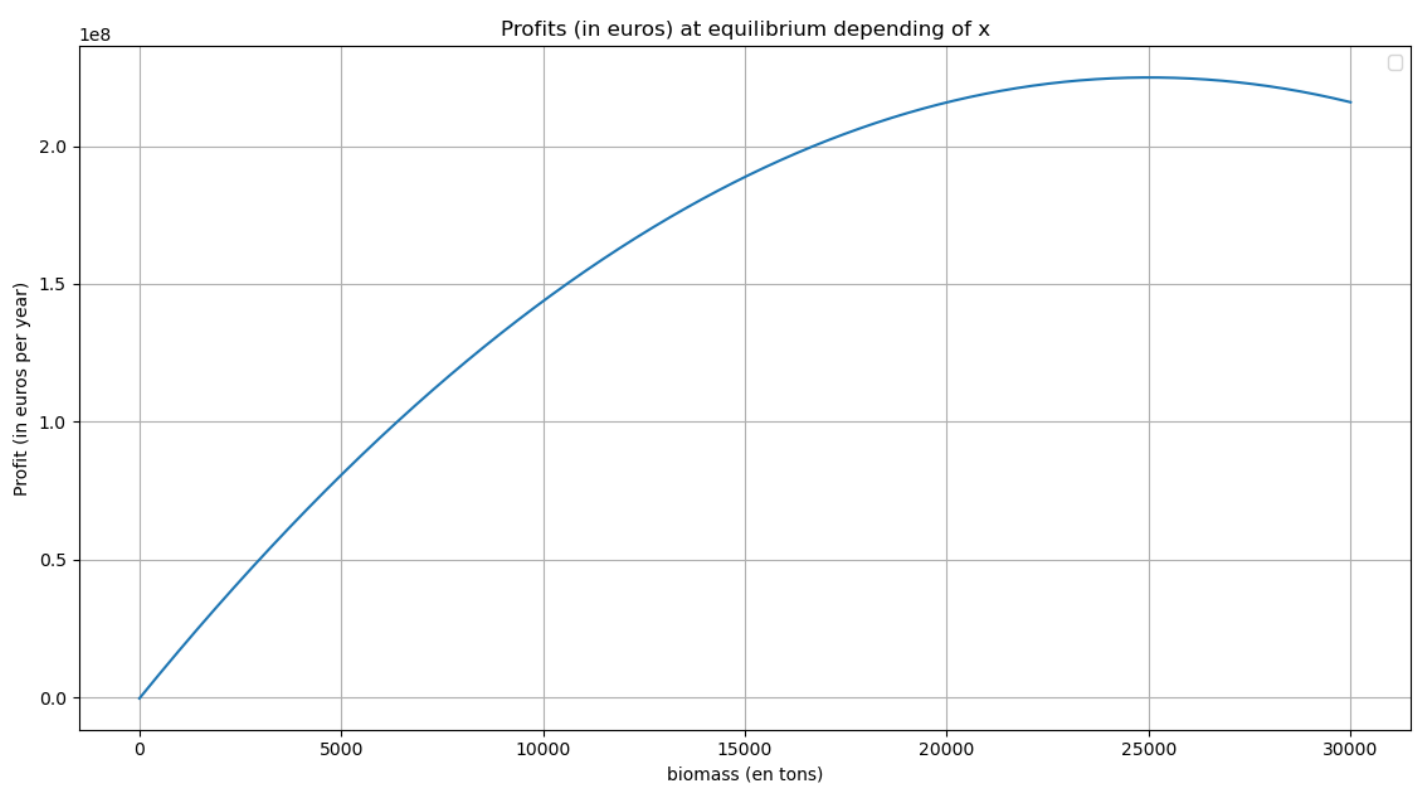

Figure 8: Gain $G_{e q}$ depending of $x$

For this to be positive, it is therefore necessary that :

$$
x \geq x_{O A}
$$

$G$ is derivable, thus :

$$
G_{e q}^{\prime}(x)=c\left(p\left(1-\frac{x}{K}\right)-\frac{1}{K}\left(p x-\frac{k}{q}\right)\right)
$$

and,

$$
\begin{aligned}
& G_{e q}^{\prime}(x)=0 \\
& \Longleftrightarrow x=\frac{K}{2}+\frac{k}{2 p q}
\end{aligned}
$$

Thus, this point, which we will call $x_{G O}$ being where the income is maximum (we can see it very well by studying the variations, see figure 7), we notice that we must maintain the resource beyond $x_{M S Y}$ to maximize the income. This corresponds, in the long run, to fishing less than the maximum possible. This remark is all the more relevant since the price often increases with the scarcity of the resource on the market (but not necessarily in the oceans), which we have not taken into account in our model. Thus, in the long term, the economic optimum is ecologically viable with our model. 


\subsection{Optimization over time}

However, what matters to the fisher is often not the long-term balance, but the total gains over time. Here we will keep the same model as in the previous subsection. It makes sense to do our study with a constant effort: it corresponds to an initial investment (fishing boats and equipment, personnel) that is difficult, because it is financially and socially costly [Le 98], to change later.

\subsubsection{The integral to maximize}

It is therefore a question for the fisherman or woman to maximize the sum of his or her income over time, i.e. to find $E$ that maximizes the integral :

$$
I_{0}(E)=\int_{t=0}^{t=+\infty} G(E, t) d t
$$

If the trade is good, this integral must diverge. To make it diverge as much as possible is to maximize the limit when $t$ tends towards the infinity of its term. So, in this case, the population to be maintained is always $x_{G O}$.

\subsubsection{Making money now rather than later: the discount rate comes into play}

However, fishers also seek to optimize their earnings as early as possible. Thus, for them, present gains are more important than future gains. The future is therefore reduced. This is why it is useful to introduce the annual discount rate $\delta \in \mathbb{R}_{+}^{*}$ Cla90. Thus, the integral to be maximized becomes :

$$
I_{\delta}(E)=\int_{0}^{+\infty} e^{-\delta t} G(E, t) d t
$$

And we have :

$$
G(E, t)=p q E x-k E
$$

i.e., $\operatorname{par}[3.2$ :

$$
G(x)=c\left(p x-\frac{k}{q}\right)\left(1-\frac{x}{K}\right)+\left(\frac{k}{q x}-p\right) \frac{d x}{d t}
$$

We pose :

$$
\begin{aligned}
z: \mathbb{R}_{+}^{*} & \rightarrow \mathbb{R} \\
x & \longmapsto \int_{x_{O A}}^{x(t)}\left(p-\frac{k}{q y}\right) d y
\end{aligned}
$$

Since the integral term is canceled in $x_{O A}$, we have :

$$
\frac{\partial z}{\partial t}=-\left(\frac{k}{q x}-p\right) \frac{d x}{d t}
$$

Because,

$$
0 \leq\left|\frac{\partial z}{\partial t}\right| e^{-\delta t} \leq\left(p-\frac{k}{q x}\right)\left|\frac{d x}{d t}\right| e^{-\delta t}
$$

Therefore, by 2.8

$$
0 \leq\left|\frac{\partial z}{\partial t}\right| e^{-\delta t} \leq p c \frac{K}{4} e^{-\delta t}
$$

We have, therefore, by comparison, convergence of the integral; we can therefore make an integration by part 


$$
\begin{aligned}
\int_{0}^{+\infty} e^{-\delta t} \frac{\partial z}{\partial t} d t & =\left[z e^{-\delta t}\right]_{0}^{+\infty}+\delta \int_{0}^{+\infty} z e^{-\delta t} d t \\
& =\delta \int_{0}^{+\infty} z(t) e^{-\delta t} d t-z(t=0)
\end{aligned}
$$

We therefore seek to maximize, subject to existence :

$$
I_{\delta}(E)=\int_{0}^{+\infty}\left(c\left(p x(t)-\frac{k}{q}\right)\left(1-\frac{x(t)}{K}\right)-\delta z(x)\right) e^{-\delta t} d t+z\left(x_{0}\right)
$$

This amounts to finding the $x_{\delta}$ towards which the population must be stretched to infinity. According to Euler's necessary condition, we have a maximum $x_{\delta}$ for $I_{\delta}\left(x_{\delta}\right)$ only if :

$$
\frac{\partial}{\partial x}\left[\left(c\left(p x(t)-\frac{k}{q}\right)\left(1-\frac{x(t)}{K}\right)-\delta z(x)\right) e^{-\delta t}\right]=\frac{d}{d t} \frac{\partial}{\partial x^{\prime}(t)}\left[\left(c\left(p x(t)-\frac{k}{q}\right)\left(1-\frac{x(t)}{K}\right)-\delta z(x)\right) e^{-\delta t}\right]
$$

i.e.

$$
\frac{\partial}{\partial x}\left[\left(c\left(p x(t)-\frac{k}{q}\right)\left(1-\frac{x(t)}{K}\right)-\delta z(x)\right) e^{-\delta t}\right]=0
$$

i.e.

$$
\frac{\partial}{\partial x}\left[c\left(p x(t)-\frac{k}{q}\right)\left(1-\frac{x(t)}{K}\right)-\delta z(x)\right]=0
$$

i.e.

$$
c\left(1-2 \frac{x}{K}\right)-\frac{k\left(1-\frac{x}{K}\right)}{p q x-k}=\delta
$$

i.e.

$$
-\frac{2 p q}{K} x^{2}+\left(p q\left(1-\frac{\delta}{c}\right)+\frac{k}{K}\right) x+k \frac{\delta}{c}=0
$$

So, as only the positive solution makes sense:

$$
x_{\delta}=\frac{K}{4 p q}\left(\frac{k}{K}+p q\left(1-\frac{\delta}{c}\right)+\sqrt{\left(\frac{k}{K}+p q\left(1-\frac{\delta}{c}\right)\right)^{2}+\frac{8 p q k}{K} \times \frac{\delta}{c}}\right)
$$

By writing this expression with $\delta=0$, we find $x_{\delta \rightarrow 0}=x_{G O}$.

We show that, if $k>0, x_{\delta}$, function of $\delta$, is decreasing on $\mathbb{R}_{+}$and decreased by 0 (see figure 9 ). Thus, by monotonous continuity, it admits a limit when $\delta$ tends towards infinity. By (43), the only possibility for this limit is $x_{\delta \rightarrow+\infty}=x_{O A}$.

We note that if the opportunity cost of the fishing effort is zero (i.e. $k=0$ ), which is quite possible [Cla06](pp.60 - 61), we have :

$$
x_{\delta}=\frac{K}{2}\left(1-\frac{\delta}{c}\right)
$$

Therefore, if the $c$ growth rate is lower than the $\delta$ discount rate, $x_{\delta}<0$. Thus, in this case, the social optimum is the extinction of the species! 


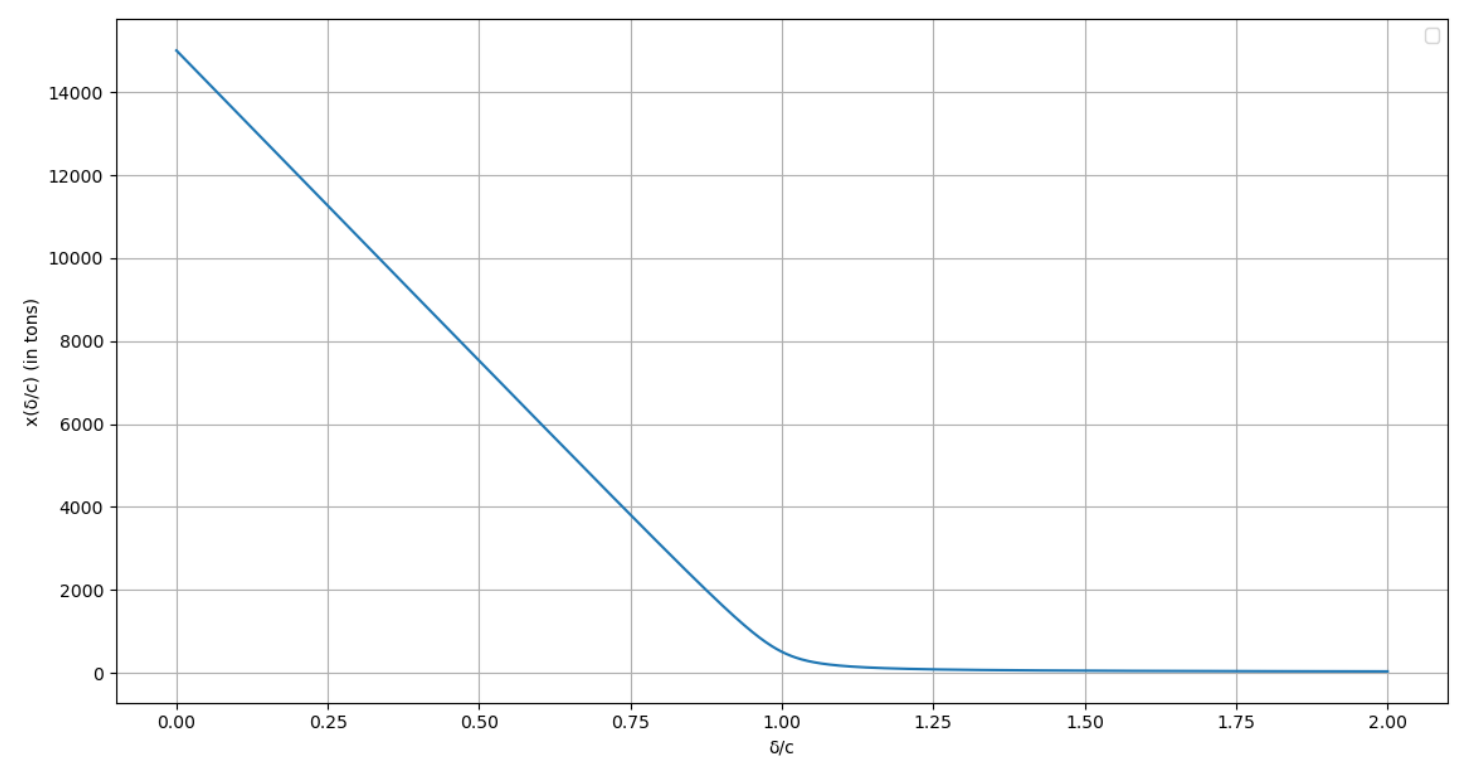

Figure 9: Socially Optimal Biomass $x_{\delta}$ according to the ratio $\frac{\delta}{c}$

\section{Limitations of a mono-specific model}

However, there are several problems in considering only the role of a single species:

1. There are critical dependencies between the growth of a population and its number due to predators, which may explain an extinction of a species not predicted by previous models [Cla06] [Cla10] ;

2. In a net, there are size problems: too young individuals of large fish can be caught at the same time as mature individuals of other species [Gob95];

3. All captures play a role in the food web. ;

4. The degradation of habitats by fishing, especially trawling Cur09. However, such degradation can be modeled on the previous model by a decrease of $c$ or $K$ over time. This therefore directly decreases the gain according to the equations of the bio-economic model studied in the previous section.

Thus, the FAO advocates for an ecosystem approach to fisheries [CC16]. To solve its problems, many software programs, such as Ecopath and the Osmosis model $[\mathrm{CS00b}]$, risk management methods such as the Monte Carlo method (see [Had11] for practical examples) and neural networks have been implemented [Guy+06]. However, such non-analytical models are outside the scope of this study.

\section{Problem with several species fished}

\subsection{Analysis of several coupled differential equations as a function of the trophic model}

Thus, to improve our biological model, we must consider three types of possible inter-specific relationships: cooperative, competitive and predation relationships. We will propose each time the analytical model, for two species (species 1 and species 2), but which can obviously be generalized to $n$ species, considered as the most complete [Cha14](chapter 5). Chapter 6 of [GR74] proposes a probabilistic resolution of these equations generalized to $N$ species, which we will not study here.

We will write our models as if the different species were caught in the same net, keeping the fishing model introduced in section 3.1 . 


\subsubsection{Cooperation}

Two species of biomass $x_{1}$ and $x_{2}$ can help each other. Using the parameters of Verhulst's equation [3.2), indexed by the species number, we can write :

$$
\left\{\begin{array}{l}
\frac{d x_{1}}{d t}=c_{1} x_{1}\left(1-\frac{x_{1}}{K_{1}}+\frac{x_{2}}{K_{1}}\right)-q_{1} E x_{1} \\
\frac{d x_{2}}{d t}=c_{2} x_{2}\left(1-\frac{x_{2}}{K_{2}}+\frac{x_{1}}{K_{2}}\right)-q_{2} E x_{2}
\end{array}\right.
$$

\subsubsection{Competition}

More frequently, two species share access to the same resource. We have, following the previous model:

$$
\left\{\begin{array}{l}
\frac{d x_{1}}{d t}=c_{1} x_{1}\left(1-\frac{x_{1}}{K_{1}}-\frac{x_{2}}{K_{1}}\right)-q_{1} E x_{1} \\
\frac{d x_{2}}{d t}=c_{2} x_{2}\left(1-\frac{x_{2}}{K_{2}}-\frac{x_{1}}{K_{2}}\right)-q_{2} E x_{2}
\end{array}\right.
$$

We notice that if the two species share the same parameters $c, K$ and $q$, then $x_{1}+x_{2}$ follows the same equations as in the monospecific model.

In both models, if one of the two populations were to become extinct, then the surviving species would follow the mono-specific model. The resolution of such non-linear differential systems can be complicated. However, a reflection on the economic optimum, as it does not require solving the system, is more easily possible.

\subsubsection{Predation}

We propose here an adaptation of the Lotka-Voltera equations taking into account the limited capacity of the medium, as in Verhulst's model (3.2). In addition, we take into account the phenomenon of resource saturation: when prey is sufficiently abundant, the growth of predators tends towards the intrinsic growth rate. We thus obtain the model of Rosenzweig-McArthur (1963).

Here, species 1 is the prey and species 2 is the predator. We note $n_{2}$ the predator's intrinsic nativity, $m_{2}$ its intrinsic mortality and $v_{2}$ its voracity. We also note $s_{12}$ the prey saturation threshold which is specific to the couple (prey, predator).

$$
\left\{\begin{array}{l}
\frac{d x_{1}}{d t}=c_{1} x_{1}\left(1-\frac{x_{1}}{K_{1}}\right)-\frac{v_{2} x_{1}}{x_{1}+s_{12}} x_{2}-q_{1} E x_{1} \\
\frac{d x_{2}}{d t}=x_{2}\left(\frac{n_{2} x_{1}}{x_{1}+s_{12}}-m_{2}\right)-q_{2} E x_{2}
\end{array}\right.
$$

In the case where the predator feeds on several species, add a coefficient in ]0.1[ before the terms of the type $\frac{x_{1}}{x_{1}+s_{12}}$.

If the only prey were to disappear, then the predator would also disappear. If the predator disappears, or stops feeding on the prey, then the prey follows the equation (3.2) mono-specific.

\subsection{Fisheries and game theory}

A possible modeling, coupling space and time with several fished species, inspired by [Kor14], consists in considering a complete graph (i.e. all the boxes are linked together) at $x_{01}+x_{02}+1$ vertices, where $x_{01}$ is the initial number of prey and $x_{02}$ that of predators. This model is also used to see the spread of disease. There are three different types of boxes on this graph:

- Boxes $\mathrm{R}$ which correspond to the individuals fished and thus to the movement of the net;

- Boxes I which correspond to the predators; 
- Boxes S which correspond to prey.

At each turn, at a fixed rate $\lambda \in \mathbb{R}_{+}^{*}$, the predator eats and thus moves towards a prey, i.e. a set of $\{I, S\}$ can become at this rate a set $\{I, I\}$. The fisher's net also moves and at constant rate 1 , a set of boxes $\{I, R\}$ becomes a set of boxes $\{R, R\}$. The question that arises is what is the probability that the prey (the $\mathrm{S}$ vertices) will disappear.

In Igor Kortchemski's mathematical study, the fisherman or woman only catches predators. This model could be improved by introducing a fourth, vacant vertex $\mathrm{V}$, which would allow prey to reproduce at a fixed rate $\mu \in \mathbb{R}_{+}^{*}$. A possible economic analysis would be to give a cost to each link according to its length and a price (corresponding to an income) for each fish caught.

\section{Conclusion: what to do? Good fisheries management, the human difficulty of public policy}

We can draw two lessons from this discussion. The first is that every model has its limits. Here we have chosen to restrict ourselves to analytical models so that we can understand what we are doing. In addition, we did not, for example, consider space as a study parameter. Many fishermen and women work on much more complex computer models. However, for each model, so that it does not turn into a catastrophe [CR97], we must systematically check its presuppositions. This is what Colin Clark insists on in his latest rewrite of Mathematical Bioeconomics [Cla10]. It is therefore important in policies that the legislator may be led to decide to apply the precautionary principle [De 98]. For example, Beverton and Holt (see [BH54]) have shown that only infinite marine reserves could have a significant impact on the evolution of a monospecific exploited population (see [STC98]). But this is no longer true in a multi-species model [CS00a]. The reserves serve in all cases as a safety catch in case the fisheries management policy proves to be bad $[\overline{\mathrm{Lau}+98} \mid[\mathrm{Cla06}]$ (voir 5.3). They may even give positive effects that modelers would not have thought of [Van17].

The second lesson is that while our models give an ideal operating curve to follow, making it follow is much more difficult. In such a complex field, mathematics must also take into account the psychology of the different actors in the fishery, as Colin Clark [Cla06] does. This can take an analytical form or go through game theory (see [RL95 for a simple model).

Acknowledgments I thank Dr. Philip Gallic for is help and the support for the first part of my work, in second year of classe préparatoire in Lycée Henri IV.

Competing interests I declare no competing interest.

Supplementary information: Code for figure can be founded on https://github.com/cvt8/fisheries

\section{References}

[Ari00] Ovide Arino. “Mathématiques appliquées à la dynamique de population”. In: Les espaces de l'halieutique. 4e Forum halieumétrique (Rennes, June 26-July 1, 1999). Ed. by Didier Gascuel, Pierre Chavanc, and Nicolas Bez. Colloques et séminaires / Institut français de recherche scientifique pour le développement en coopération. Association française d'halieumétrie. Paris: IRD, Institut de recherche pour le développement, 2000, pp. 21-39. ISBN: 2-7099-1461-1.

[AS10] Lee G. Anderson and Juan Carlos Seijo. Bioeconomics of Fisheries Management. Wiley, 2010. ISBN: 9780-8138-1732-3.

[BH54] Raymond J.H. Beverton and Sidney J. Holt. On the dynamics of exploited fish populations. With a forew. by Sidney J. Holt. reprint of 1st ed., cop. 1957, 1983 Caldwell (N.J.), Blackburn press, 2004. Facsim ed., 1954. ISBN: 1-930665-94-6 (br.)

[CC16] Philippe Cacaud and Shannon Cosentino-Roush. Guide pratique pour légiférer en vue d'une approche écosystémique des pêches. Rome: FAO, 2016. ISBN: 978-92-5-209344-2. uRL: http://www . fao .org/3/ a-i5966f.pdf (visited on 04/12/2020). 
[Cha14] Jean-René Chazottes. Modélisation mathématiques pour l'environnement et l'économie. MAP 556, année 2014-2015. Version 6 juin 2014. Ecole polytechnique. 2014. URL: https ://www . cpht . polytechnique . $\mathrm{fr} / \mathrm{sites} /$ default/files/livre.pdf (visited on 04/13/2020). Notes de cours.

[Cla06] Colin Whitcomb Clark. The Worldwide Crisis in Fisheries. Economic models and human behaviour. Cambridge University press, 2006. ISBN: 0-521-54939-6.

[Cla10] Colin Whitcomb Clark. Mathematical bioeconomics. The mathematics of conservation. 3rd ed. Pure and applied mathematics. Wiley, 2010. ISBN: 978-0-470-37299-9 (rel.)

[Cla90] Colin Whitcomb Clark. Mathematical bioeconomics. The optimal management of renewable resources. 2nd ed. Pure and applied mathematics. Wiley, 1990. ISBN: 0-471-50883-7.

[CR97] Joseph Catanzano and Hélène Rey. "La recherche halieutique entre science et action : réflexions sur fond de crise / Fisheries research at the crossroads of science and action : reflection in a context of crisis." In: Natures sciences sociétés (Montrouge) 2 (1997), p. 19. ISSN: 1240-1307. URL: https : //www . nss-journal.org/articles/nss/pdf/1997/02/nss19970502p19.pdf (visited on 04/12/2020).

[CS00a] Philippe Cury and Yunne-Jai Shin. "Modélisation de l'impact des zones refuges sur une ressource multispécifique”. In: Les espaces de l'halieutique. 4e Forum halieumétrique (Rennes, June 26-July 1, 1999). Ed. by Didier Gascuel, Pierre Chavanc, and Nicolas Bez. Colloques et séminaires / Institut français de recherche scientifique pour le développement en coopération. Association française d'halieumétrie. Paris: IRD, Institut de recherche pour le développement, 2000, pp. 201-214. ISBN: 2-7099-1461-1 (br.)

[CS00b] Philippe Cury and Yunne-Jai Shin. "Osmose, un modèle individu-centré spatialement explicite des dynamiques halieutiques multispécifiques”. In: Les espaces de l'halieutique. 4e Forum halieumétrique (Rennes, June 26-July 1, 1999). Ed. by Didier Gascuel, Pierre Chavanc, and Nicolas Bez. Colloques et séminaires / Institut français de recherche scientifique pour le développement en coopération. Association française d'halieumétrie. Paris: IRD, Institut de recherche pour le développement, 2000, pp. 171199. ISBN: 2-7099-1461-1 (br.)

[Cur09] Philippe Cury. "Sortir de la crise halieutique”. Français. In: Pour la science 377 (Mar. 2009), pp. 16-17.

[Cur14] Philippe Cury. "Pour une gestion durable des pêches". In: Problèmes économiques 3084 (Feb. 2014). Extrait de Responsabilité et environnement - annales des Mines, pp. 20-27.

[De 98] William De La Mare. “Tidier Fisheries Management Requires a New MOP (Management-oriented Paradigm).” In: Reviews in Fish Biology and Fisheries 8.3 (1998), p. 349. ISSN: 09603166. URL: https : //api-istexfr . accesdistant . sorbonne- universite . fr/ark: /67375/VQC-M1PZNOBM - 4/fulltext . pdf? auth=ip, fede\&sid=ebsco, istex-view (visited on 04/12/2020).

[DL95] Jean-Louis Durant and Claude Lobry. "Modèles mathématiques d'une espèce structurée en deux stades dans un environnement variable". In: Les recherches françaises en évaluation quantitative et modélisation des ressources et des systèmes halieutiques. Colloque (Rennes, June 29-July 1, 1993). Ed. by Didier Gascuel, Jean-Louis Durand, and Alain Fonteneau. ENSAR halieutique, ORSTOM, and IFREMER. Bondy: ORSTOM, 1995, pp. 75-84. ISBN: 2-7099-1259-7.

[FAO18] FAO. La situation mondiale des pêches et de l'aquaculture. 2018. URL: http : / / www . fao . org/3/ i9540fr/I9540FR.pdf (visited on 04/12/2020).

[Fel40] Willy Feller. "On the logistic law of growth and its empirical verifications in biology." In: Acta Biotheoretica 5.2 (1940), p. 51. ISSN: 00015342. URL:https://team.inria.fr/modemic/files/2015/09/ ArticleFeller.pdf (visited on 04/13/2020).

[FPR95] Jocelyne Ferraris, Dominique Pelletier, and Marie-Joëlle Rochet, eds. Méthodes d'étude des systèmes halieutiques et aquacoles. deuxième Forum halieumétrique (Nantes, June 26-28, 1995). Paris: ORSTOM, 1995. ISBN: 2-7099-1357-7.

[Gas95] Didier Gascuel. "Effort et puissances de pêche : redéfinition des concepts et exemples d'application". In: Les recherches françaises en évaluation quantitative et modélisation des ressources et des systèmes halieutiques. Colloque (Rennes, June 29-July 1, 1993). Ed. by Didier Gascuel, Jean-Louis Durand, and Alain Fonteneau. ENSAR halieutique, ORSTOM, and IFREMER. Bondy: ORSTOM, 1995, pp. 159-181. ISBN: 2-7099-1259-7. 
[GCB00] Didier Gascuel, Pierre Chavanc, and Nicolas Bez, eds. Les espaces de l'halieutique. 4e Forum halieumétrique (Rennes, June 26-July 1, 1999). Colloques et séminaires / Institut français de recherche scientifique pour le développement en coopération. Association française d'halieumétrie. Paris: IRD, Institut de recherche pour le développement, 2000. ISBN: 2-7099-1461-1 (br.)

[GDF95] Didier Gascuel, Jean-Louis Durand, and Alain Fonteneau, eds. Les recherches françaises en évaluation quantitative et modélisation des ressources et des systèmes halieutiques. Colloque (Rennes, June 29July 1, 1993). ENSAR halieutique, ORSTOM, and IFREMER. Bondy: ORSTOM, 1995. ISBN: 2-7099-12597.

[Gob95] Bertrand Gobert. "Évaluation des ressources récifales aux Antilles : le défi de la multi spécificité". In: Les recherches françaises en évaluation quantitative et modélisation des ressources et des systèmes halieutiques. Colloque (Rennes, June 29-July 1, 1993). Ed. by Didier Gascuel, Jean-Louis Durand, and Alain Fonteneau. ENSAR halieutique, ORSTOM, and IFREMER. Bondy: ORSTOM, 1995, pp. 93-103. ISBN: 2-7099-1259-7.

[GR74] Narendra S. Goel and Nira Richter-Dyn. Stochastic models in biology. Academic Press, 1974. Chap. 6. ISBN: 0-12-287460-9.

[Guy+06] David Guydmard et al. "La modélisation pour la compréhension de déplacement de grands pélagiques exploités par la pêche”. In: Michel Petit and Frédéric Huynh. Halieutique et environnement océanique. le cas de la pêche palangrière à l'espadon depuis l'île de la Réunion. Paris: IRD, 2006, pp. 133-153. ISBN: 2-7099-1583-9.

[Guy98] Olivier Guyader. "Simulation de la mise en œuvre de quotas individuels transférables et application à la pêche germonière”. In: Daniel Thiel. La dynamique des systèmes: complexité et chaos. Systèmes complexes. Hermès, 1998. Chap. 7. ISBN: 978-2866017286.

[Had11] Malcom Haddon. Modelling and quantitative methods in fisheries. 2nd ed. Chapman, Hall, and CRC, 2011. xvi + 449. ISBN: 978-1-58488-561-0.

[Hol04] Sidney J. Holt. "Foreward to the 2004 printing”. In: Raymond J.H. Beverton and Sidney J. Holt. On the dynamics of exploited fish populations. With a forew. by Sidney J. Holt. reprint of 1st ed., cop. 1957, 1983 Caldwell (N.J.), Blackburn press, 2004. Blackburn press, 2004. ISBN: 1-930665-94-6 (br.)

[HW01] Ray Hilborn and Carl J. Walters. Quantitative fisheries stock assessment. choice, dynamics, and uncertainty. Ed. by Dordrecht. Boston ; London: Kluwer Academic, 2001. ISBN: 1-4020-1845-2 (br.)

[Kor14] Igor Kortchemski. Sur un modèle de type proie-prédateur. (DMA - École Normale Supérieure Journées MAS - Toulouse). Aug. 2014. URL: http://www . math . univ-toulouse .fr/ agarivie/Telecom/ slidesMAS/Kortchemski_MAS2014_bio.pdf (visited on 04/12/2020).

[Lau+98] Tim Lauck et al. "Implementing the Precautionary Principle in Fisheries Management Through Marine Reserves." In: Ecological Applications 8.1 (1998), S72. ISSN: 10510761. URL: https : // esajournals . onlinelibrary.wiley.com/doi/epdf/10.1890/1051-0761\%281998\%298\%5BS72\%3AITPPIF\%5D2. 0. C0\%3B2 (visited on 04/12/2020).

[Lau81] Le Guen Jean-Claude Laurec Alain. Dynamique des populations marines exploitées. Tome 1. Concepts et modèles. Ed. by CNEXO. Article. FRANCE, 1981. URL: https://archimer . ifremer.fr/doc/00000/ 1126/ (visited on 04/12/2020).

[Le 98] Pascal Le Floc'h. "Modélisation et simulation du comportement d'investissement des entreprises de pêche : la prise en compte de l'innovation". In: Daniel Thiel. La dynamique des systèmes: complexité et chaos. Systèmes complexes. Hermès, 1998. Chap. 6. ISBN: 978-2866017286.

[Mal09] Thomas Robert Malthus. Essai sur le principe de population. chez J.J. Paschoud, 1809.

[Pau97] Daniel Pauly. Méthodes pour l'évaluation des ressources halieutiques. Français. Trans. Anglais by Jacques Moreau. Toulouse, 1997. ISBN: 2-85428-444-5.

[PH06] Michel Petit and Frédéric Huynh. Halieutique et environnement océanique. le cas de la pêche palangrière à l'espadon depuis l'île de la Réunion. Paris: IRD, 2006. ISBN: 2-7099-1583-9.

[Que93] Jacques Quensière. “De la modélisation halieutique à la gestion systémique des pêches”. In: Natures Sciences Sociétés 3 (1993), p. 211. 
[RL95] Bruno Romagny and Claude Lobry. “À propos des relations stock-recrutement”. In: Méthodes d'étude des systèmes halieutiques et aquacoles. deuxième Forum halieumétrique (Nantes, June 26-28, 1995). Ed. by Jocelyne Ferraris, Dominique Pelletier, and Marie-Joëlle Rochet. Paris: ORSTOM, 1995, pp. 219224. ISBN: 2-7099-1357-7.

[Sch91] Milner Schaefer. "Some aspects of the dynamics of populations important to the management of the commercial Marine fisheries." In: Bulletin of Mathematical Biology 53.1/2 (1991). Reprinted from the Bulletin of the Inter-American Tropical Tuna Commission, Vol. 1(2), pp. 27-56 (1954) with the permission of the Inter-American Tropical Tuna Commission, p. 253. ISSN: 00928240. URL: https: // api istex-fr.accesdistant. sorbonne-universite.fr/ark:/67375/1BB-TCS1KRC2-Z/fulltext . pdf?auth=ip, fede\&sid=ebsco, istex-view (visited on 04/13/2020).

[STC98] Guénette Sylvie, Lauck Tim, and Clark Colin. "Marine Reserves: from Beverton and Holt to the Present". In: Reviews in Fish Biology and Fisheries 3 (1998), p. 251. ISSN: 0960-3166. URL: https : / / linkspringer-com.accesdistant.sorbonne-universite.fr/content/pdf/10.1023/A:1008859130275. pdf (visited on 04/13/2020).

[TG95] Suzanne Touzeau and Jean-Luc Gouzé. "Variations sur le thème de la modélisation de la « tragédie » du libre accès aux ressources renouvelables”. In: Méthodes d'étude des systèmes halieutiques et aquacoles. deuxième Forum halieumétrique (Nantes, June 26-28, 1995). Ed. by Jocelyne Ferraris, Dominique Pelletier, and Marie-Joëlle Rochet. Paris: ORSTOM, 1995, pp. 253-257. ISBN: 2-7099-1357-7.

[van+06] J.C.J.M. van den Bergh et al. Bioeconomic Modelling and Valuation of Exploited marine Ecosystems. English. Springer, 2006. ISBN: 1402040415.

[Van17] Erick Vance. “Au Mexique, des micro-réserves pour repeupler l'Océan”. In: National Geographic 216 (Sept. 2017). URL: https : / / wWw . nationalgeographic . fr/environnement/au - mexique - des micro-reserves-pour-repeupler-locean (visited on 04/12/2020).

[Ver38] Pierre-François Verhulst. "Notice sur la loi que la population suit dans son accroissement". In: Correspondance mathématique et physique 10 (1838), pp. 113-121. URL: https : / books . google .fr / books $? \mathrm{hl}=\mathrm{fr} \& \mathrm{id}=8 \mathrm{GsEAAAAYAAJ} \& \mathrm{jtp}=113 \&$ redir_esc $=\mathrm{y} \# \mathrm{v}=$ onepage \& $\mathrm{q} \& \mathrm{f}=\mathrm{fal}$ se (visited on 04/12/2019). 
Table 1: Data for the various models

\begin{tabular}{lccl}
\hline Object & Unit & Symbol & Value \\
\hline Initial population & ton & $x_{0}$ & 10000 \\
Growing rate & year $^{-1}$ & $\mathrm{c}$ & 1,2 \\
Capacity of the environment & ton & $K$ & 30000 \\
Capturability & & $q$ & 0,2 \\
Selling price & euro/ton & $p$ & 15000 \\
Annual cost for one unit of fishing effort & euro & $k$ & 50000 \\
\hline
\end{tabular}

Table 2: Numerical calculation of relevant values for figure analysis

\begin{tabular}{lc}
\hline Data & Value \\
\hline$x_{M S Y}$ & 15000 \\
MSY & 9000 \\
$h_{\max }$ for $x_{0}=16000$ (Verhlust) & 8960 \\
$h_{\max }$ for $x_{0}=10000$ (Verhlust) & 8000 \\
$E_{\max }$ & 6 \\
$x_{O A}$ & 16,67 \\
$x_{G O}$ & 15008,33 \\
\hline
\end{tabular}

